\title{
Characterization and modeling of organic thin-film transistors based $\pi$-conjugated small molecule tetraphenyldibenzoperiflanthene: Effects of channel length
}

\author{
W.Boukhilia, ${ }^{\text {, }}$, M. Mahdouania ${ }^{a}$ R. Bourguiga ${ }^{a}$, J. Puigdollers ${ }^{b}$ \\ ${ }^{a}$ Laboratoire de Physique des Matériaux : Structure et Propriétés, GroupePhysique des \\ Composants et DispositifsNanométriques, Faculté des sciences de Bizerte, 7021 \\ Jarzouna-Bizerte, Université de carthage, Tunisia. \\ ${ }^{b}$ Departmentd'EnginyeriaElectronica, UniversitatPolitecnica de Catalunya, C/Jordi \\ Girona, Modul C4, Barcelona-08034, Spain.
}

\begin{abstract}
P-type organic thin filmtransistors (OTFTs) with different channel lengths have been fabricatedand characterized by thermal evaporation using the smalltetraphenyldibenzoperiflanthene (DBP) as an active material on $\mathrm{Si} / \mathrm{SiO}_{2}$ substrate. The influence of the channel length onthe electrical performance of DBP based organic thinfilm transistors (DBP-TFTs) prepared with bottom gate-bottom contact in the linear and saturation regimeswere systematically examined in this work. All devices showed a significant increase in the output and transfer drain current as the channel lengths was decreased in the linear and saturation regimes. We have reported the variation of the electrical parameterssuch as transconductance $\left(\mathrm{g}_{\mathrm{m}}\right)$, fieldeffect mobility ( $\mu$ in and $\left.\mu_{\mathrm{sat}}\right)$, contacts and total resistances $\left(\mathrm{R}_{\mathrm{C}}\right.$ and $\mathrm{R}_{\mathrm{T}}$ ), threshold voltage $\left(\mathrm{V}_{\text {th }}\right)$, total trap density $\left(\mathrm{N}_{\text {trap }}\right)$, subthreshold slope (SS), the interface trap density $\left(\mathrm{D}_{\mathrm{it}}\right)$, turn-on voltage $\left(\mathrm{V}_{\mathrm{on}}\right)$ and the ratio current ( $\left.\mathrm{I}_{\mathrm{on}} / \mathrm{I}_{\text {off }}\right)$ by channel length variation which are extracted from the experimental electrical data current-voltage of DBP-TFTs. We found that the field effect mobility is extremely dependent on the channel length dimensions. We also show that for smaller channel length, it results a good mobilityand a good ratio current of the DBP-TFTs with a short channel length (good saturation mobility and current ratio $\mu_{\text {sat. } \max }=3 \times 10^{-2} \mathrm{~cm}^{2} \mathrm{~V}^{-1} \mathrm{~s}^{-1}, 1.6 \times 10^{4}$, respectively,for $\mathrm{L}=2.5 \mu \mathrm{m}$ ). The developed model shows a good agreement with the measured data for all values of channel lengths (L).
\end{abstract}

Keywords: channel lengtheffects; $\pi$-conjugatedsmall-molecule; DBP -TFTs; modeling

* Corresponding author: wboukehili@yahoo.fr(W.Boukhili) 


\section{Introduction}

During these last years, organic semiconductors have attracted comprehensive interest among researchers all over the world, in particular the use of organic compounds in electronic applications has known an awesome evolutionmostly in the organic thinfilm transistors (OTFTs), which have drawn a great attention by the research area because they are one of the most important devices in electronics and they lie at the heart of modern computing due to their many advantages over conventional inorganic electronics such aslight-weight, low cost processing, large area capability, structural flexibility and low temperature process [1-3].The fabrication technology of OTFTs has improved considerably in recent years. Presently, the electrical performance of the OTFTs made from the small-molecule organic semiconductors(pentacene, N, N'-ditridecylperylene-3, 4, 9, 10- tetracarboxylicdiimide (PTCDI- $\left.\mathrm{C}_{13} \mathrm{H}_{27}\right)$, fullerene $\left(\mathrm{C}_{60}\right)$, 1, 4, 5, 8-naphthalene tetracarboxylicdianhydride (NTCDA))are similar to hydrogenated amorphous silicon (a-Si:H) TFTs. Accordingly, the organic small molecules based OTFTs are more widely popular and they have already demonstrated their potentials toward organic electronic applications such as gas sensors, smart cards, active-matrix displays, radio-frequency identification tags (RFID), HD-TVs, image sensors, iPodsand flexible microelectronics [4-9]. The effects of extrinsic factors such as illumination, temperature and humidity [10-15] and the nature of the gate dielectric surface properties [16-18]that directly affect the performance and drift of OTFTs has been widely studied.The understanding of material transport properties and the characterization of the injecting properties of the metal-semiconductor interface are a crucial interest in the fabrication of efficient devices including especially the effects that result from the device size miniaturization. Therefore, the miniaturization of device dimensions such as the channel lengths effects on electrical performances of organic thin film transistors have been previously reported[19-23].It was found that decreasing channel length resulted in significant degradation of transistor electrical performance. Another most important factor which drops mobility under high gate voltages and which degrade the performances of the thin film transistors is the interface quality between the organic semiconductors and the metalwhich constitutes the source-drain electrodes. Generally speaking, the main origin of the contact resistance in the p-type OTFTs is the mismatch between the work function of the sourcedrain electrodes and the energy levels of the organic semiconductors [24-26]. The resistance effects are directly related to the increase of the charge carrier density in the channel of the 
transistor. Several methods have been developed for the extraction of the contact resistance in OTFTs[27-28].

The main aim of this present work is to study the channel length variation effectson the electrical stability ofthe tetraphenyldibenzoperiflanthenebased OTFTs with $\mathrm{SiO}_{2}$ as a gate insulator in the linear and the saturation regimes.Accordingly, we have extracted the various electrical parameters of DBP-TFTs with different channel lengths from experimental data. Finally, we have developed an analytical model in order to reproduce the experimental characteristics current-voltage (output and transfer) of the studied DBP-TFTs for several channel lengths ranging from $2.5 \mu \mathrm{m}$ to $20 \mu \mathrm{m}$.

\section{Experimental details}

The chemical molecular structure of thetetraphenyldibenzoperiflanthene(DBP) organic semiconductor with a molecular formula of $\mathrm{C}_{64} \mathrm{H}_{36}$ and a molecular weight of $804.97 \mathrm{~g} / \mathrm{mol}$ and with purity $98 \%$ is shown in fig. 1(a).The material was commercially available from Sigma Aldrich chemicaland it was used without any further purification process. The schematic diagram of bottom gate bottom contact (BGBC) type of the fabricated DBP-TFTs is shown in fig. 1(b).Ann-doped crystalline silicon wafer was used both as a substrate and a bottom-gate electrode (BG) for this experimental work. The gate dielectric layer for all devices is a thermally grown $230 \mathrm{~nm}$ thick $\mathrm{SiO}_{2}$ layer. For the source and drain (S/D) electrodes, Au (30nm)/ITO (3nm) double layer was used and patterned by conventional liftoff technique.The organic active layers of DBP were deposited by thermal evaporation in a high vacuum chamber with a base pressure of $5 \times 10^{-6}$ mbar on the source and drain (S/D) electrodes for a bottom contacts structure. The deposition rate was around $0.5 \AA / \mathrm{s}$ and the total deposited thickness was $50 \mathrm{~nm}$ measured by means of a surface profilometer(VeecoDektak 150).In order to investigate the effects of the geometric dimensions on electrical performances of our devices, the DBP-TFTs were prepared with several channel lengths (L) which were varied in the range $2.5 \mu \mathrm{m}, 5 \mu \mathrm{m}, 10 \mu \mathrm{m}$ and $20 \mu \mathrm{m}$ and the channel width (W) was fixed at $2000 \mu \mathrm{m}$.All the electrical measurements of the fabricated devices were measured in vacuum conditions $\left(10^{-1}\right.$ mbar $)$ under dark using HP5156 parameter analyzer.

In order to gain aninsight on the morphological stability of DBP, the morphology of the DBP films was studied by using an atomic-force microscopy (AFM).The surface morphology properties of the DBP $(50 \mathrm{~nm})$ deposited on a $\mathrm{SiO}_{2}$ layer has been investigated by AFM. Fig.2shows an atomic force microscopy image of the DBP films deposited on the n-Silicon substrate inside the conducting channel (a)and outside the conducting channel (b). As seen 
infig. 2, the DBP thin films are formed from small crystal grains with a grain size of 100$300 \mathrm{~nm}$ which are distributed almost homogeneously on silicon surface. As shown by the atomic force microscopy (AFM) images in fig. 2(a) and (b), in both regions (inside and outside channel) the DBP organic semiconductor form a well-ordered polycrystalline film, which is a prerequisite for obtaining a good carrier charge mobility.

\section{Results and discussion}

\section{Output characteristics of the DBP-TFTs with different channel lengths}

Figs. 3(a)-(d) show the output characteristics ( $I_{D}$ vs. $V_{D}$ ) curves of the DBP-TFTs with channel lengths ranging from $2.5 \mu \mathrm{m}$ to $20 \mu \mathrm{m}(\mathrm{L}=2.5 \mu \mathrm{m}, 5 \mu \mathrm{m}, 10 \mu \mathrm{m}$ and $20 \mu \mathrm{m})$ at a fixed channel width (W) of $2000 \mu \mathrm{m}$. Devices were measured under vacuum by varying the drain voltage $\left(\mathrm{V}_{\mathrm{D}}\right)$ from 0 to $-80 \mathrm{Vwith}-0.8$ Vincrements for different gate voltages $\left(\mathrm{V}_{\mathrm{G}}\right)$ from 0 to $-60 \mathrm{~V}$ with $-10 \mathrm{~V}$ increments. As seen in figs. 3(a)-(d), the drain current ( $\left.\mathrm{I}_{\mathrm{D}}\right)$ increases linearly at lownegative drain voltages $\left(V_{D}\right)$ and thereafter IDbecomes saturated at high drain voltages due to a pinch-off of the organic active channel of the fabricated devices. We note as well that the drain current increases with negative gate voltages $\left(V_{G}\right)$. All resulting output characteristics for DBP-TFTs with various channel lengths showed typical p-channel operation mode with a clear saturation behavior at high negative drain voltages $\left(V_{D}\right)$ and complied well with the standardequations of the fieldeffect transistorsoperating in the accumulation mode. The accumulated charges in the conductive channel are holes. These reasons indicate that the DBP is a p-type charge transport material (the majority carriers are holes).

Fig. 3(e) depicts the output characteristics (ID vs. VD) curves of the DBP-TFTsat $V_{G}=$ $60 \mathrm{Vwith}$ channel lengths varied from $\mathrm{L}=2.5$ to $20 \mu \mathrm{m}$.As illustrated in fig. $3(\mathrm{e})$, the output current increases with decreasing the channel length at a fixed gate voltage $\left(\mathrm{V}_{\mathrm{G}}=-60 \mathrm{~V}\right)$. This behavior can be explained by the reduction in channel resistance with decreasing channel length which allows increase the density of charge carriers in the conductive channel of DBPTFTs.

\section{Transfer characteristics and extraction of key parameters of the DBP-TFTs in the linear and saturation regimes}

In order to gain a deeper understanding of the charge carrier transport in the active organic layer of thin film transistors several parameters such as transconductance $\left(\mathrm{g}_{\mathrm{m}}\right)$,fieldeffect 
$\operatorname{mobility}\left(\mu_{\text {lin }}\right.$ and $\left.\mu_{\text {sat }}\right)$, contacts $\operatorname{resistance}\left(R_{c}\right)$,threshold $\operatorname{voltage}\left(V_{\text {th }}\right)$,total trap $\operatorname{density}\left(\mathrm{N}_{\text {trap }}\right)$,subthreshold slope(SS), interface trap density( $\left.\mathrm{D}_{\mathrm{it}}\right)$,turn-on voltage( $\left.\mathrm{V}_{\text {on }}\right)$ and the ratio current $\left(\mathrm{I}_{\mathrm{on}} / \mathrm{I}\right.$ off) are introduced and they are extracted below. These parameters are necessary to study the charge carries transport and the characterization of the injection properties of the metal-organic semiconductor interface in these types of devices.

\subsection{In linear regime}

Infig. 4(a), we plottedthe transfer characteristics (ID versusV $V_{G}$ )of the DBP-TFTs with different channel lengths in the linear regime measured at a fixed drain voltage $\left(\mathrm{V}_{\mathrm{D}}=-5 \mathrm{~V}\right)$ and by varying the gate voltage $\left(\mathrm{V}_{\mathrm{G}}\right)$ from 0 to $-60 \mathrm{Vwith}-0.6 \mathrm{~V}$ increments.Fig. 4(a) shows that the drain current in the linear regime $\left(V_{D}=-5 \mathrm{~V}\right)$ significantly increasesas the channel lengths was decreased from $20 \mu \mathrm{m}$ to $2.5 \mu \mathrm{m}$.

\subsubsection{Transconductance and fieldeffect mobilityin linear regime}

Transconductance $\left(\mathrm{g}_{\mathrm{m}}\right)$ of a device represents the amplification delivered by the device and is defined as the variation of the drain current $\left(\mathrm{ID}_{\mathrm{D}}\right)$ with the gate voltage $\left(\mathrm{V}_{\mathrm{G}}\right)$ at fixed drain voltage $\left(V_{D}\right)$. The transconductancegmcan be calculated from the following equation [29]:

$$
g_{m}=\left[\frac{\delta I_{D}}{\delta V_{G}}\right]_{V_{D=c t e}}=\frac{W}{L} \mu_{l i n} C_{i} V_{D}(1)
$$

whereWand Lare the channel's width and length of the transistor, respectively, $\mathrm{C}_{\mathrm{i}}$ is the insulator capacitance (per unit area), $V_{D}$ is the drain voltage which equals to $-5 \mathrm{~V}$ and $\mu_{\text {lin }}$ is the field effect mobility in the linear regime.

The variation of transconductance $\mathrm{g}_{\mathrm{m}}$ as a function $\mathrm{V}_{\mathrm{GO}}$ f the DBP-TFTs with different channel lengths is shown infig 4(b).We found that $\mathrm{g}_{\mathrm{m}}$ increases linearly with gate voltage and decreases at high negatives $V_{G}$ for all devices. This decrease is generally due tothe presence of contact resistance $\left(\mathrm{R}_{\mathrm{c}}\right)$ whose will discuss below[30].

\subsubsection{Mobility in linear regime}

In order to study the effect of the channel length variation on the field effect mobility of the charge carrier in DBP-TFTs at low drain voltage $\left(\mathrm{V}_{\mathrm{D}}=-5 \mathrm{~V}\right)$. The field effect mobility inthe 
lowfield linear regionis then extractedfrom the transconductancefor each channel length by the following equation[31]:

$$
\mu_{\text {lin }}=\frac{L}{C_{i} V_{D} W}\left[\frac{\delta I_{D}}{\delta V_{G}}\right]_{V_{D=c t e}}=\frac{L}{C_{i} V_{D} W} g_{m}(2)
$$

The extracted field effect mobility in linear regime as function $V_{G}$ curves of the DBP-TFTs with different channel lengths is shown infig 4(c).From fig. 4(c), we have extracted the maximum mobility in the linear regime $\left(\mu_{\text {lin.max }}\right)$ for each channel length DBP-TFTs and they are depicted in fig 4(d). As seen in fig. 4(d), the maximum mobility in the linear regime increases with decreasing the channel length.From fig $4(\mathrm{c})$,we found that $\mu_{\text {lin }}$ increases linearly with gate voltage and decreases at high negatives $V_{G}$ for all devices. This decrease in field effect mobility was mainly due to drain current reduction by contact resistance $\left(\mathrm{R}_{\mathrm{c}}\right)$ between metal (S-D electrodes)/organic semiconductorinterface[29-30].

\subsubsection{Contact resistance in DBP-TFTs}

Contact resistance between organic semiconductor and metals can dominate the transport properties of electronic devices incorporating such materials. The contact resistance can be caused by the formation of a high resistivity area near the drain and source electrodes. The latter can form a severe barrier for the injection of chargecarrier. In order to study the effect of the contact resistance oncharge carrier injection in the organic active layer, the transfer line method (TLM) was used to calculate the resistance [32]. Thus the total resistance $\left(\mathrm{R}_{\mathrm{T}}\right)$ of our DBP-TFTs was extracted from the linear region at $\mathrm{V}_{\mathrm{D}}=-5 \mathrm{~V}$ in the output characteristics for different high negative gate voltages $\left(\mathrm{V}_{\mathrm{G}}=-30 \mathrm{~V},-40 \mathrm{~V},-50 \mathrm{~V}\right.$ and $\left.-60 \mathrm{~V}\right)$ and for several channel lengths. $\mathrm{R}_{\mathrm{T}}$ can be expressed as the sum of two types of resistance, namely the channel resistance and the contact resistance according with the following equation [33-34]:

$$
R_{T}=R_{C}+R_{c h}=R_{C}+\frac{L}{W C_{i} \mu_{F E T, l i n}\left(V_{G}-V_{t h}\right)}(3)
$$

where the contacts resistance $\left(R_{c}\right)$ is sum of source and drain contact resistance $R_{S}$ and $R_{D}$, respectively, and $R_{c h}$ is the channel resistance.

According to transmission line method (TLM), the intersection of Y-axis with the total resistance $\left(\mathrm{R}_{\mathrm{T}}\right)$ versus $\mathrm{L}$ curve when the channel length becomes zero gives the value of $\mathrm{R}_{\mathrm{c}}[35$ -

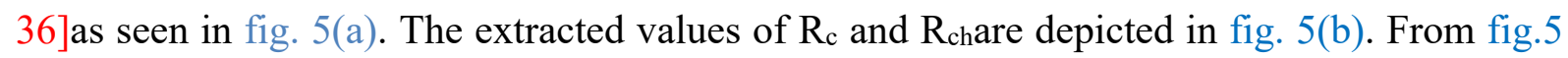
(a) and (b), we can see that the $R_{c}$ gate voltage dependency is generally correlated with the 
increase of charge carrier concentration which introduces the current in the organic active layer of our DBP-TFTs at higher $V_{G}$ values.As can be seen, the contact resistance for each device is heavily gate voltage dependent,which essentially is due to an increase of the charge carrier density near the contacts that act as contact doping.This contact resistance can be seen to be related to preventthe transport of charges from source-drain the electrodes to the accumulation layer, and will strongly depend on the local morphology of the semiconductor, which in the case of bottom contact OTFTs itself can strongly depend on the dimension device geometry such as channel length [24]. By reducing the channel length, the channel resistance is also reduced and the nonlinear effects caused by the contacts become more prominent. Moreover, the channel resistance decreases with increasing gate-source voltage, due to the increasing of the induced charge carrier in the channel of DBP-TFTs. Indeed, when $\mathrm{L}$ decreases, $\mathrm{R}_{\mathrm{C}}$ becomes not negligible compared to $R_{C h}$ and tends to reduce the transconductance and the mobility of the DBP-TFTs at high negative gate voltages.

\subsection{In saturation regime}

The transfer characteristic ( $\mathrm{I}_{\mathrm{D}}$ vs. $\mathrm{V}_{\mathrm{G}}$ ) of the studied DBP-TFTs with different channel lengthsin saturation regime $\left(\mathrm{V}_{\mathrm{D}}=-70 \mathrm{~V}\right)$ is shown in fig.6(a). As see in fig6(a), the saturated drain current increased remarkablyas the channel length decreases. This behavior is predominantly attributed to an increase of fieldeffect mobility values which, as mentioned below, is probably an indication of grain boundary limited charge transport for long channel lengths. It is well known that the mobility is extremely sensitive to the grain size in TFTs basedorganic semiconductors [12].Indeed, for the longchannel length ( $\mathrm{L}=20 \mu \mathrm{m})$ the grain boundaries in the active channel appear as centers of traps for free charge carriers that can explain the decrease of the drain current as channel length increased to $20 \mu \mathrm{m}$ (fig. 6(a)).

\subsubsection{The threshold voltage and trapped charge density}

Typically, the threshold voltage $\left(\mathrm{V}_{\text {th }}\right)$ is determined as the applied gate voltage needed to achieve measurable channel current flow.Severalextractionproceduresareused to

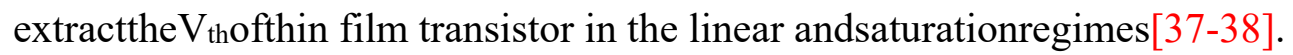

Indeed, in the linear regime (lowdrainvoltage)the most commonusedisthesecond-derivative (SD) method of thedraincurrent in respect to thegatevoltage $\left(\left[\frac{\delta g_{m}}{\delta V_{G}}\right]_{V_{D=c t e}}=\left[\frac{\delta^{2} I_{D}}{\delta^{2} V_{G}}\right]_{V_{D=c t e}}\right)$. 
In thismethod, the $\mathrm{V}_{\text {thvalue }}$ is defined as thegatevoltagewherethederivative of thetransconductance $\left(\mathrm{g}_{\mathrm{m}}\right)$ in respect to thegatevoltage has a maximum (the data arenotshown). Theobtainedvalues of theVth in the linear regimearedepicted in fig. 4(e).

At high drain voltage (saturation regime $V_{D}=-70 \mathrm{~V}$ ), the threshold voltage $\left(\mathrm{V}_{\text {th }}\right)$ values of DBP-TFTs for various channel lengths were determined from the plot of square root of the drain current versus gate voltage $\left(\left|I_{D, \text { sat }}\right|^{1 / 2}\right.$ vs. $\left.V_{G}\right)$ under $V_{D}=-70 \mathrm{~V}$ as shown in fig. 6(b). The relationship between the threshold voltage $\left(\mathrm{V}_{\text {th }}\right)$ and the channel length is shown in the inset part in fig. 6(b).It's notedthat there is a slight difference between the obtained values of the threshold voltage in the linear regime and those in saturation regime (as seen in fig. 4(e) and fig. 6(b)). This behavior can be due to the square root of the drain current used to extract the threshold voltage in the saturation regime, and to a lesser extent to the value of $V_{D}$ used for its measure[38].

It's found that the $\mathrm{V}_{\text {thwas }}$ shifted to positive gate voltages when decreasing the channel length. The same behavior has been observed in the pentacene based TFTs [39].One of result of the decreases of channel length is the shift of the threshold voltage towards positive voltages. In other words, if $\mathrm{L}$ becomes relatively short $(\mathrm{L}=2.5 \mu \mathrm{m}$ and $5 \mu \mathrm{m})$ and the contact resistance decreases, a most important number of charge carriers crossingthe organic active layer because the transit time decreased $\left(\mathrm{L} \propto \mathrm{t}^{2}\right)$. Such behavior can also be explained by the reduction of the potential barrier at metal/semiconductor organic interface in the depletion regime which promotes the injection of holes[39-40].

Generally speaking, the shift of the threshold voltage in organic TFTsis directly related to the trapped chargedensityat the insulator- organic semiconductor interface [41]. The total trap density for the transistorcan be determined by the following relation[42]:

$$
N_{\text {trap }}=\left|\frac{V_{t h} C_{i}}{q}\right|
$$

whereq is the elementary charge. The obtainedvalues of $\mathrm{N}_{\text {trap }}$ are reported in table 1.

\subsubsection{Saturation mobility}

In order to have a deeper insight on the effects of channel lengths on the performances of DBP-TFTs, the fieldeffect mobility which is one of the main important parameters that defines the TFTs quality and directly determines device performance to a large extent is examined.In the saturation regime $\left(\mathrm{V}_{\mathrm{D}}=-70 \mathrm{~V}\right)$, the experimental saturation mobility was determined using the following relation: 


$$
\mu_{s a t}=\frac{2 L}{W C_{i}}\left(\frac{\partial \sqrt{|\mathrm{ID}|}}{\partial V_{G}}\right)^{2}
$$

Fig. 7(a) shows the experimental saturation mobility versus $V_{G}$ for all devices. It found that the experimental saturation mobility of the DBP-TFTs increases when the channel length decreasesfrom $20 \mu \mathrm{m}$ to $2.5 \mu \mathrm{m}$. This behavior is less observed for $\mathrm{L}=10 \mu \mathrm{m}$ and $\mathrm{L}$ $=20 \mu \mathrm{m}$.Indeed, the maximum value of the extracted saturation mobility obtained from the plot

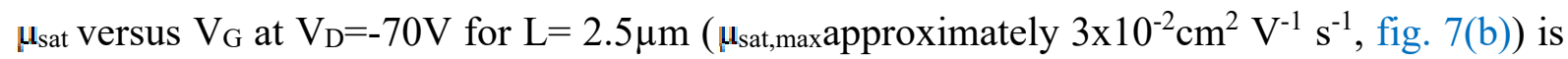
decreased by approximately $44 \%$ ( $\mu_{\text {sat,max }}$ approximately $1.3 \times 10^{-2} \mathrm{~cm}^{2} \mathrm{~V}^{-1} \mathrm{~s}^{-1}$, fig. 7(b)) after increasing the channel length to $20 \mu \mathrm{m}$ ( as seen in fig. 7(b)).For smaller channel length (like $\mathrm{L}$ $=2.5$ and $5 \mu \mathrm{m}$ ), it results a high speed of operation of the DBP-TFTs.From the fig. 7(b), it is evaluated that the DBP-TFTs giveshigher saturation mobility with a smaller channel length value which exhibits better performance.Moreover, we found that the $\mu_{\text {sat }}$ increases linearly with $\mathrm{V}_{\mathrm{G}}$ then becomes saturated for high negatives $\mathrm{V}_{\mathrm{G}}$, this behavior can be attributed to the increase in charge carrier density in the conductive channel at high negatives $V_{G}$. The fabricated DBP-TFTs in this work show a good electrical performance in terms of field effect mobility $\left(\mu_{\mathrm{FE}}=3 \times 10^{-2} \mathrm{~cm}^{2} \mathrm{~V}^{-1} \mathrm{~s}^{-1}\right.$ for $\left.\mathrm{L}=2.5 \mu \mathrm{m}\right)$, which is among the highest performance reported for DBP-TFTs[43].

\subsubsection{Extraction of thesubthreshold slope, interface trap density, the turn-on voltage and the ratio current $I_{o n} / I_{o f f}$}

For a better understanding of channel length variation effects on the performance of the fabricated devices, we have extracted all transistor electrical parameters for each channel length.

One of these parameters is the subthreshold slope (SS) that gives the characteristics below the threshold regime and provides a measure of how well the device turns from the off state to the on state and can be closely related to the density of the interface trap at the semiconductor/isolator interface in the thin film transistor, which can be determined by the following relation[44]:

$$
S S=\left[\frac{\operatorname{dlog}\left(I_{D}\right)}{d V_{G}}\right]^{-1}
$$

As seen in table 1, the parameter SS changes with channel length that can suggests the existence of trap centers located at the interface of the $\mathrm{SiO}_{2} / \mathrm{DBP}$. It is well known that the 
interface quality between an organic semiconductor/isolator plays a crucial role on the performance of the OTFTs. The density of the interface trap in the DBP-TFTs can be determinedby the following equation [45-46]:

$$
D_{i t}=\left[\frac{\operatorname{sSlog}(e)}{K T / q}-1\right] \frac{C_{i}}{q}
$$

whereTis the temperature, $\mathrm{k}$ is Boltzmann's constantand qis the electronic charge.

As shown in table 1 , the turn-on voltage $\left(\mathrm{V}_{\text {on }}\right)$ was positively shifted and the ratio current increased as the channel length decreased. Indeed, the positive shifts in the turn-on voltage can be explained by the drain induced barrier lowering effect (DIBL)[40]. Another important parameter for improving the performance of OTFTs is the current ratio Ion/ Ioff. This ratio describes the ability of a device to switch from the on state to the off state.

The obtained values of SS, $\mathrm{I}_{\text {on }} / \mathrm{I}_{\text {offand }} \mathrm{V}_{\text {onare }}$ extracted by tracing the variation of the drain current in logarithmic scale versus $V_{G}$ at $V_{D}=-70 V\left(\log \left|I_{D}\right|\right.$ versus $\left.V_{G}\right)$, as seen in fig. (8).All electrical parameters such as trapped charge density, subthreshold slope (SS), the interface

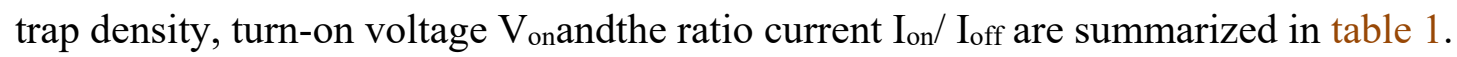

\section{Modeling of current-voltage characteristics of DBP-TFTs}

Significant progress has been made towards improved understanding of the electrical properties in various types of thin film transistors (TFTs) including a-Si, poly-Si and organic TFTs. Several analytical models have been proposed to describe electrical behaviors and to reproduce the experimental electrical characteristics current-voltageof various organic field effect transistors[47-51]. Moreover,many methods are used for extracting electrical parameters of these kinds of devices [52-56].

According to the conventional crystalline semiconductor MOSFETs theory, thestandard TFTs equations of drain currentas function of the drain voltage $\left(V_{D}\right)$ and the gate voltage $\left(V_{G}\right)$ in the linear and saturation regimes are given by the following equations[57-58]:

$$
I_{D}=\left\{\begin{array}{lcc}
\frac{W}{L} C_{i} \mu_{F E T}\left(V_{G}-V_{t h}-\frac{V_{D}}{2}\right) V_{D} & \text { linear regime if } & \left|V_{G}-V_{t h}\right|>\left|V_{D}\right| \\
\frac{W}{2 L} C_{i} \mu_{F E T}\left(V_{G}-V_{t h}\right)^{2} & \text { saturated regime if } & \left|V_{G}-V_{t h}\right|<\left|V_{D}\right|
\end{array}\right.
$$

whereW is the width of channel, $\mathrm{L}$ is the channel length, $\mathrm{C}_{\mathrm{i}}$ is the capacitance of the oxide layer, $\mathrm{V}_{\text {th }}$ is the threshold voltage and $\mu_{\text {FETis }}$ the field effect mobility. 


\subsection{Contact resistance effects and equivalent circuit of DBP-TFT}

The non-ohmic contact effects frequently appear in TFTs based on amorphous semiconductors.As mentioned earlier, in the case of the OTFTs with relatively short-channel lengths these effects become more important and even degrade the electrical performance of the OTFTs.As a result, the resistances of both drain and source contacts, represent a particularly relevant parameter for OTFTs, influencing its overall performance in terms of conductance[59-60]. In addition, the adhesion to substrate, particularly for bottom contacts needs to be taken into account. A further improvement consists of taking account for the source and drain contacts resistancein the modeling of these types of devices.

Indeed, the gate voltage $V_{G}$ is not equal to the gate to source voltage $V^{\prime}{ }_{G}$ because source terminal is not grounded but its potential is raised by the amount $\mathrm{R}_{S} \mathrm{I}_{\mathrm{D}}$ by the current $\mathrm{I}_{\mathrm{D}}$ flowing through Rs,moreover for the drain voltage $V_{D}$ is not equal to the drain to source voltage $\mathrm{V}_{\mathrm{D}}^{\prime}$ because the source terminal is not grounded and the drain terminal is connected to $\mathrm{V}_{\mathrm{D}}$ throughR $\mathrm{R}_{\mathrm{D}}$ so that the gate and drain voltage expressions are writtenas follows $[48,61]$ :

$$
\left\{\begin{array}{c}
\mathrm{V}_{G}^{\prime}=\mathrm{V}_{\mathrm{G}}-\mathrm{R}_{\mathrm{S}} \mathrm{I}_{\mathrm{D}}=\mathrm{V}_{\mathrm{G}}-\frac{\mathrm{R}_{\mathrm{C}}}{2} \mathrm{I}_{\mathrm{D}} \\
\mathrm{V}_{\mathrm{D}}^{\prime}=\mathrm{V}_{\mathrm{D}}-\left(\mathrm{R}_{\mathrm{S}}+\mathrm{R}_{\mathrm{D}}\right) \mathrm{I}_{\mathrm{D}}=\mathrm{V}_{\mathrm{D}}-\mathrm{R}_{\mathrm{C}} \mathrm{I}_{\mathrm{D}}
\end{array}\right.
$$

where $R+R_{D}=R_{C}$ is the contact resistance.

Fig. 9 depicts an equivalent circuit of DBP-TFT in which the contact resistance effects that modified the drain current have been taken into account in series with channel resistance $\mathrm{R}_{\mathrm{ch}}[48,62]$. According to this equivalent circuit and the expressions of contacts resistancethat are given by equation (9), the drain current is treated as a function $V^{\prime}{ }_{G}$ and $V^{\prime}{ }_{D}$ and can be written as follows:

$$
I_{D}=\left\{\begin{array}{lll}
\frac{W}{L} C_{i} \mu_{F E T}\left(\mathrm{~V}_{\mathrm{G}}^{\prime}-V_{t h}-\frac{\mathrm{V}_{\mathrm{D}}^{\prime}}{2}\right) \mathrm{V}_{\mathrm{D}}^{\prime} & \text { linear regime } & \left|\mathrm{V}_{\mathrm{G}}^{\prime}-V_{t h}\right|>\left|\mathrm{V}_{\mathrm{D}}^{\prime}\right|_{(10)} \\
\frac{W}{2 L} C_{i} \mu_{F E T}\left(\mathrm{~V}_{\mathrm{G}}^{\prime}-V_{t h}\right)^{2} & \text { saturated regime } & \left|\mathrm{V}_{\mathrm{G}}^{\prime}-V_{t h}\right|<\left|\mathrm{V}_{\mathrm{D}}^{\prime}\right|
\end{array}\right.
$$

Unlike crystalline field effect devices, carrier mobility in OFETs is gate bias dependent. In an attempt to take into account the mobility dependence with gate voltage in the parameter extraction, several groups have used an empirical relation of the field-effect mobility as[54, 63]:

$$
\mu_{\mathrm{FET}}=\mu_{0}\left(\left|\frac{\mathrm{V}_{\mathrm{G}}-\mathrm{V}_{\mathrm{th}}}{\mathrm{V}_{\mathrm{aa}}}\right|\right)^{\gamma}
$$


where $\mu_{0}$ is the voltage independent mobility and it is often considered as the band mobility for the material of the TFT under analysis[63], $\mathrm{V}_{\text {th }}$ is the threshold voltage. $\mathrm{V}_{\text {aa }}$ and $\gamma$ are empirical parametersdefining the variation of mobility with gate voltage. Parameter $\gamma$ is associated with the conduction mechanism of the device and it depends on doping density and dielectric permittivity of the organic semiconductor material. Therefore, $\gamma$ can be used to describe physical mechanisms that are present in OTFTs.

By substituting $\mathrm{R}_{\mathrm{C}}$ and $\mu_{\mathrm{FET}}$ that are given previously by (9) and (11), respectively in equation (10), we obtain the following expressions for the drain current $I_{D}$ in both regimes $[61,64]$ :

$$
\begin{gathered}
I_{D, \text { lin }}=\frac{\left(\left(W\left(\mu_{0} / V_{a a}^{\gamma}\right) C_{i}\left(V_{G}-V_{t h}\right)^{\gamma}\right) / L\left\{V_{D}\left(V_{G}-V_{t h}\right)-(1 / 2) V_{D}^{2}\right\}\right)}{1+\left(\left(W\left(\mu_{0} / V_{a a}^{\gamma}\right) C_{i}\left(V_{G}-V_{t h}\right)^{\gamma}\right) / L\right)\left\{-V_{D} R_{c} / 2+V_{D}\left(V_{G}-V_{t h}\right)\right\}} \\
I_{D, s a t}=\frac{\left(\begin{array}{l}
\mu_{0} \\
W C_{i}\left(V_{0 a}^{\gamma}\right)\left(V_{G}-V_{t h}\right)^{\gamma} R_{C}^{2}
\end{array}\right.}{1+\frac{W\left(V_{a a}^{\gamma}\right) C_{i} R_{c}}{2 L}\left(V_{G}-V_{t h}\right)^{\gamma+1}} \\
\left.-\sqrt{1+\frac{W\left(\mu_{0} / V_{a a}^{\gamma}\right) C_{i} R_{c}}{L}\left(V_{G}-V_{t h}\right)^{\gamma+1}}\right\}
\end{gathered}
$$

By using the proposed expressions of the analytical model, we have able calculate the transfer and output current-voltage curves for different values of L ranging from 2.5 to $20 \mu \mathrm{m}$. The set of parameters that give a close agreement between the measured data and those obtained by the model are summarized in Table 2. Figs.10 (a)-(b) show the comparison of the measured transfer characteristics in the linear $\left(\mathrm{V}_{\mathrm{D}}=-5 \mathrm{~V}\right)$ and the saturated $\left(\mathrm{V}_{\mathrm{D}}=-70 \mathrm{~V}\right)$ regimes, respectively, with the calculated data of our DBP-TFTs for each values of L. Theobtained close agreements between the measured output characteristics and calculated withaccording to the model of DBP-TFTs for different channel lengths are shown in figs. 11 (a)-(d). The used analytical model is proved to be accurate enough to explain the charge transport and it is 
verified to be accurate in describing direct current characteristicsin these kinds of components.

\section{Conclusions}

The p-small molecule DBP based organic thin film transistors with bottom-gate bottomcontact structurewere successfully fabricated and were characterized. The exploitation of experimental curves obtained on the DBP based thinfilm transistors (TFTs) for each channel length have confirmed the effects of channel length variation on the electrical performance of OTFTs in the linear andsaturation regimes and enabled us to determine the electrical parameters of the fabricated devices.It is found that the electrical parameters such as transconductance, threshold voltage, trapped charge density, subthreshold slope, interface trap density, turn-on voltage, current ratio and field effect mobility present a significant improvement when channel length is decreased.We have also investigated the influence of the total device resistance which is extracted by using the TLM method on the electrical parameters of the studied DBP-TFTs. On the other hand, based on our experimental observations, DBP-TFT with relatively short channel (in the case of $\mathrm{L}=2.5 \mu \mathrm{m}$ ) exhibited better performance in terms of the drain current, transconductance and mobility. Experimental electrical results such as output and transfer characteristics for all devices with variable channel lengths ranging from $2.5 \mu \mathrm{m}$ to $20 \mu \mathrm{m}$ have been analyzed and modeled and a good agreement with the proposed model is found.

\section{References}

[1] C.L. Fan, P.C. Chiu, C.C. Lin, IEEE Electron Dev. Lett. 31 (2010) 1485.

[2] C.L. Fan, Y.Z. Lin, W.D. Lee, S.J. Wang, C.H. Huang, Org. Electron. 13 (2012) 2924. 
[3] C.Y. Wei, F. Adriyanto, Y.J. Lin, Y.C. Li, T.J. Huang, D.W. Chou, Y.H. Wang, IEEE Electron. Dev. Lett. 30 (2009) 1039.

[4] B. Crone, A. Dodabalapur, A. Gelperin, L. Torsi, H.E. Katz, A.J. Lovinger, Z. Bao, Appl. Phys. Lett. 78 (2001) 2229.

[5] M.C. Hamilton, J. Kanicki, IEEE J. Sel. Topics. Quantum Electron. 10 (2004) 840.

[6] H.E. Katz, Chem. Mater. 16 (2004) 4748.

[7] H. Nakanotani, S. Akiyama, D. Ohnishi, M. Moriwake, M. Yahiro, T. Yoshihara, S. Tobita, C. Adachi, Adv. Funct. Mater. 17 (2007) 2328.

[8] M. Berggren, D. Nilsson, N.D. Robinson, Nature Mater. 6 (2007) 3.

[9] M. H. Chung, J. H. Kwon, T. Y. Oh, S. J Lee, D. H. Choi, B. K. Ju, Thin Solid Films 518(2010) 6289.

[10] B. Gunduz, Omar A. Al-Hartomy, Said A Farha Al Said, Ahmed A. Al-Ghamdi, F. Yakuphanoglu, Synth. Met. 179 (2013) 94-115.

[11] J. Puigdollers, M. D. Pirriera, A. Marsal, A. Orpella, S. Cheylan, C. Voz, R. Alcubilla, Thin Solid Films 517 (2009) 6271-6274.

[12] F. Yakuphanoglu, W. A. Farooq, Synth. Met. 161 (2011) 132-135.

[13]J. Park, L. Do, J. Bae, Y. Jeong, C. Pearson, M. Petty, Org. Electron. 14 (2013) 21012107.

[14] W. Boukhili, M. Mahdouani, M. Erouel, J. Puigdollers, R. Bourguiga, Synth. Met. 199 (2015) 303-309.

[15] W. Boukhili, M. Mahdouani, R. Bourguiga, J. Puigdollers, Microelectron. Eng. 150 (2016) 47-56.

[16] S. Zorai, S. Mansouri, R. Bourguiga, Superlattice. Microst. 55 (2013) 211-221.

[17] Y. Kanbur, M. I. Vladu, E. D. Głowacki, G. Voss, M. Baumgartner, G. Schwabegger, L. Leonat, M. Ullah, H. Sarica, S. Erten-Ela, R. Schwödiauer, H. Sitter, Z. Küçükyavuz, S. Bauer, N. S. Sariciftci, Org. Electron. 13 (2012) 919-924.

[18] C. Tozlu, S. Erten-Ela, Th. B. Singh, N. S. Sariciftci, S. Içli, Synth. Met. 172 (2013) 510.

[19] J.N. Haddock, X. Zhang, S. Zheng, Qing Zhang, S. R. Marder, B. Kippelen, Org. Electron. 7 (2006) 45-54.

[20] W. Boukhili, M. Mahdouani, R. Bourguiga, J. Puigdollers, Superlattices Microstruct. 83 (2015) 224-236. 
[21] T. Hirose, T. Nagase, T. Kobayashi, R. Ueda, A. Otomo, H. Naito, Appl. Phys. Lett97 (2010) 083301.

[22] Y. Xu, P. R. Berger, J. Appl. Phys. 95 (2004) 1497.

[23] C. Di, G. Yu, Y. Liu, Y. Guo, W. Wu, D. Wei, D. Zhu, Phys. Chem. Chem. Phys. 10 (2008) 17.

[24] M. Luisier, A. Schenk, W.Fichtner, Appl. Phys. Lett. 90 (2007) 102103.

[25] M. Halik, H. Klauk, U. Zschieschang, G. Schmid, Dehm C, M. Schutz, S. Maisch, F. Effenberger, M. Brunnbauer, F. Stellacci. Nature 431 (2004) 963.

[26] Y. Wang, S. Jia, Z. J. Chen, L. Ji, J. Chin. Phys. 15 (2006) 2297.

[27] R. Bourguiga. M. Mahdouani, S. Mansouri, G. Horowitz, Eur. Phys. J. Appl. Phys. 39 (2007) 7-16.

[28] Y. JinLin, B. ChiehHuang, Microelectron. Eng. 103 (2013) 76-78.

[29] G.Horowitz, R. Hajlaoui, D. Fichou, A. El Kassmi, J. Appl. Phys. 85 (1999) 3202.

[30] S. Mansouri, M. Mahdouani, A. Oudir, S. Zorai, S. Ben Dkhil, G. Horowitz, R. Bourguiga, Eur. Phys. J. Appl. Phys. 48 (2009) 30401.

[31] R. Bourguiga, F. Garnier, G. Horowitz, R. Hajlaoui, P. Delannoy, M. Hajlaoui, H. Bouchriha, Eur. Phys. J. Appl. Phys. 14 (2001) 121.

[32]X. G. Yu, J. S. Yu, J. L. Zhou, H. Wang, L. H. Cheng, and Y. D. Jiang, Jpn. J. Phys. Lett. 50 (2011) 104101.

[33] G. Horowitz, P. Lang, M. Mottaghi, H. Aubin, Adv. Funct. Mater.14 (2004) 1069-1074.

[34] B. Stadlober, U. Haas, H. Gold, A. Haase, G. Jakopic, G. Leising, N. Koch, S. Rentenberger, E. Zojer, Adv. Funct. Mater. 17 (2007) 2687-2692.

[35] D.J. Gundlach, L. Zhou, J.A. Nichols, T.N. Jackson, P.V. Necliudov, M.S. Shur, J. Appl. Phys. 100 (2006) 024509.

[36] J. Zaumseil, K. W. Baldwin, J. A. Rogers, J. Appl. Phys. 93 (2003) 6117.

[37] A. O. Conde, F. J. G. Sánchez, J. Muci, A. T. Barrios, J. J. Liou, Ch. S. Ho, Microelectron.Reliab. 53 (2013) 90-104.

[38] A. O. Conde, F. J. G. Sánchez, J. Muci, A. S. González, J. A. Martino, P. G. D. Agopian, C.Claeys, Solid StateElectron.93 (2014) 49-55.

[39] J. B. Koo, J. H. Lee, C. H. Ku, S. C. Lim, S. H. Kim, J. W. Lim, S. J.Yun, T. Zyung, Synth. Met. 156 (2006) 633-636.

[40] J. B. Kuo, S. C. Lin, Low-Voltage SOI CMOS VLSI Device and Circuits, John Wiley \& Sons, New York, 2001, p. 23. 
[41] A. Bolognesi, M. Berliocchi, M. Manenti, A.D. Carlo, P. Lugli, K. Lmimouni, C. Dufour, IEEE Trans. Electron. Dev. 51 (2004) 1997.

[42] K.P. Pernstich, S. Haas, D. Oberhoff, C. Goldmann, D.J. Gundlach, B. Batlogg, A.N. Rashid, G. Schitter, J. Appl. Phys. 96 (2004) (11) 6431.

[43] S. Galindo, M. Ahmadpour, L. G. Gerling, A. Marsal, C. Voz, R. Alcubilla, J.Puigdollers,Org. Electron.15 (2014) 2553-2560.

[44] L.A. Majewski, M. Grell, Synth. Met. 151 (2005) 175.

[45] G. Horowitz, Adv. Funct. Mater. 13 (2003) 53.

[46] R.N. Christopher, C.D. Frisbie, D.A. da Silva Filho, J.L. Bredas, C.E. Paul, R.M. Kent, Chem. Mater. 16 (2004) 4436.

[47] M.C.J.M. Vissenberg, M. Matters, Phys. Rev. B 57 (1998) 12964-12967.

[48] S. Mansouri, M. Mahdouani, A. Oudir, S. Zorai, S. Ben Dkhil, G. Horowitz, R. Bourguiga, Eur. Phys. J. Appl. Phys. 48 (2009) 30401.

[49] G. Horowitz, R. Hajlaoui, H. Bouchriha, R. Bouirguiga, M. Hajlaoui, Adv. Mater. 10 (1998) 923-927.

[50] Brijesh Kumar, B.K. Kaushik, Y.S.Negi, S.Saxena, G.D.Varma, Microelectronics Journal 44 (2013) 736-743.

[51] S. Mansouri, R. Bourguiga, A.A. Al-Ghamdi, F. Al-Hazmi, O. A. Al-Hartomy, F. ElTantawy, F. Yakuphanoglu, Synth. Met.162 (2012) 1681- 1688.

[52] W. E. Spear, P.G. Le Comber, J. Non-Cryst. Solids 727 (1972) 8-10.

[53] G. Horowitz, M.E. Hajlaoui, R. Hajlaoui, J. Appl. Phys. 87 (2000) 4456.

[54] S. Mansouri, G. Horowitz, R. Bouirguiga, Synth. Met.160 (2010) 1787-1792.

[55] S. Mansouri, S. Zorai, R. Bourguiga, Synth. Met.162 (2012) 231-235.

[56] F. Yakuphanoglu, S. Mansouri, R. Bourguiga, Synth. Met.162 (2012) 918-923.

[57] R.F. Pierret, Semiconductor Device Fundamentals, Addison-Wesley PublishingCompany, 1996.

[58] S.M. Sze, Physics of Semiconductor Devices, second ed., John Wiley \& Sons, 1981.

[59] P.V. Necliudov, M.S. Shur, D.J. Gundlach, T.N. Jackson, J. Appl. Phys. 88 (2000) 65946597.

[60] A. Cerdeira, M. Estrada, B. Iniguez, J. Pallarès, L.F. Marsal, Solid StateElectron. 48 (2004) 103-109.

[61] P. Mittal, B. Kumar, Y. S. Negi, B. K. Kaushik, R. K. Singh, Microelectronics Journal 43 (2012) 985-994. 
[62] D. Hong, G.Yerubandi, H.Q.Chiang, M. C. Spiegelberg, J.F.Wager, Crit. Rev. Solid State Mater. Sci. 33 (2008) 101-132.

[63] M. Estrada, A. Cerdeira, J. Puigdollers, L. Resendiz, J. Pallares, L.F. Marsal, C. Voz, B. Iniguez, Solid State Electron. 49 (2005) 1009-1016.

[64] B. Kumar, B. K. Kaushik, Y. S. Negi, S. Saxena, G. D. Varma, Microelectronics Journal 44 (2013) 736-743. 


\section{Figures captions:}

Figure1.A schematic view of the: (a) Molecular structure of tetraphenyldibenzoperiflanthene(DBP) (b) Bottom Gate Bottom Contact DBP-TFTs with its bias condition.

Figure 2. Atomic Force Microscopy images of the DBP (50nm) thin-films deposited on $\mathrm{SiO}_{2}$ layer: (a) inside the conducting channel (b)Outside the conducting channel.

Figures 3(a)-1(d). Output characteristics curves of DBP-TFTs with different channel lengths $(\mathrm{L}=2.5 \mu \mathrm{m}, 5 \mu \mathrm{m}, 10 \mu \mathrm{m}$ and $20 \mu \mathrm{m})$.

Figure 3.e. Output characteristics of the DBP-TFTsatV $V_{G}=-60 V$ with different channel lengths.

Figure 4.a. Transfer characteristics (ID versus $V_{G}$ plots) measured in the linear regime at $V_{D}=$ -5 Vfor different channel lengths ( $\mathrm{L}=2.5 \mu \mathrm{m}, 5 \mu \mathrm{m}, 10 \mu \mathrm{m}$ and $20 \mu \mathrm{m})$.

Figure 4.b. Transconductance $g_{m}$ as function $V_{G o f}$ the DBP-TFTs with different channel lengths $(\mathrm{L}=2.5 \mu \mathrm{m}, 5 \mu \mathrm{m}, 10 \mu \mathrm{m}$ and $20 \mu \mathrm{m})$.

Figure 4.c. The field effect mobility in DBP-TFTs in linear regime $\left(V_{D}=-5 V\right)$ versus $V_{G}$ for all devices.

Figure 5. Total device resistances $\left(\mathrm{R}_{\mathrm{T}}\right)$ versus channel length $(\mathrm{L})$ of the DBP-TFTs at different high negative gate voltages.

Figures6. (a)-(b). (a) Transfer characteristics IDversus $V_{G}$ plots measured in the saturation regime at $V_{D}=-70 \mathrm{~V}$ for all DBP-TFTs. (b) Square root of $\left|I_{D}\right|$ from which the threshold voltage was determined for each channel length. The inset depicts threshold voltage $\left(\mathrm{V}_{\text {th }}\right)$ vs. L.

Figure 7.Experimental saturation mobility versus $\mathrm{V}_{\mathrm{G}}$ for each channel length.

Figure 8. The variation of the drain current in logarithmic scale versus $V_{G}$ in the saturation regime $\left(\log \left|I_{D}\right|\right.$ vs. $\left.V_{G}\right)$ for all DBP deviceswhere it's illustratedthe extraction method of the

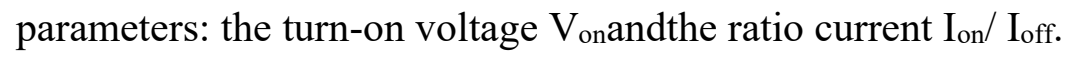

Figure 9. Electrical equivalent circuit of OTFTs proposed by the used model that include the channel resistance and contact resistances in series with the source and drain terminals, respectively.

Figures 10. (a)-(b). Measured (circle line) and modeled (full line) transfer characteristics of DBP-TFTs: (a) in the linear regime $\left(V_{D}=-5 \mathrm{~V}\right)$ and (b) in the saturation regime $\left(\mathrm{V}_{\mathrm{D}}=-70 \mathrm{~V}\right)$.

Figures 11. (a)-(d). The good agreement between experimental (circle line) and that obtained from model (full line) output characteristics: (a) $\mathrm{L}=2.5 \mu \mathrm{m}$, (b) $\mathrm{L}=5 \mu \mathrm{m},(\mathbf{c}) \mathrm{L}=10 \mu \mathrm{mand}(\mathbf{d}) \mathrm{L}=20 \mu \mathrm{m}$ of DBP based TFTs. 


\section{Tables captions:}

Table 1. Experimental electrical parameters of DBP-TFTs with different channel lengths.

Table 2.Parameter values that give good agreement between the measured characteristics and those obtained by the model. 


\begin{tabular}{|c|c|c|c|c|c|}
\hline $\mathrm{L}_{\mathrm{L}(\mathrm{um})}$ Parameters & $\begin{array}{l}N_{\text {trap }} \\
\left(\mathrm{cm}^{-2}\right)\end{array}$ & $\begin{array}{c}\text { SS } \\
(\mathbf{V} / \text { dec })\end{array}$ & $\begin{array}{r}D_{\text {it }} \\
\left(\mathrm{cm}^{-2} \mathrm{eV}^{-1}\right)\end{array}$ & $\begin{array}{l}V_{\text {on }} \\
(\mathrm{V})\end{array}$ & $\mathbf{I}_{\mathrm{on}} / \mathbf{I}_{\text {off }}$ \\
\hline $\mathrm{L}=2.5 \mu \mathrm{m}$ & $2.1 \times 10^{12}$ & 10 & $1.87 \times 10^{13}$ & -13.5 & $1.6 \times 10^{4}$ \\
\hline $\mathrm{L}=5 \mu \mathrm{m}$ & $2.15 \times 10^{12}$ & 6.75 & $1.27 \times 10^{13}$ & -15 & $6.5 \times 10^{3}$ \\
\hline $\mathrm{L}=10 \mu \mathrm{m}$ & $2.25 \times 10^{12}$ & 4.57 & $8.55 \times 10^{12}$ & -16.5 & $2.5 \times 10^{3}$ \\
\hline $\mathrm{L}=\mathbf{2 0} \mu \mathrm{m}$ & $2.35 \times 10^{12}$ & 2.2 & $4.12 \times 10^{12}$ & -17.5 & $1.5 \times 10^{3}$ \\
\hline
\end{tabular}

Table. 1.

\begin{tabular}{|c|c|c|c|c|c|}
\hline $\mathbf{L}(\mu \mathrm{m})$ & $\mathrm{V}_{\mathrm{aa}}(\mathrm{V})$ & $\gamma$ & $\mu_{0}\left(\mathrm{~cm}^{2} \mathrm{~V}^{-1} \mathrm{~s}^{-1}\right)$ & $\mathrm{V}_{\text {th }}(\mathrm{V})$ & $\mathrm{R}_{\mathrm{c}}(\mathrm{K} \Omega)$ \\
\hline $\mathbf{L}=\mathbf{2 . 5} \boldsymbol{\mu m}$ & & & & & \\
\hline $\mathbf{L}=\mathbf{5} \boldsymbol{\mu m}$ & 2.3 & 0.3 & $6 \times 10^{-5}$ & -17.5 & $5 \times 10^{6}$ \\
\hline $\mathbf{1 0} \boldsymbol{\mu m}$ & 6 & 0.94 & $5.75 \times 10^{-6}$ & -20.5 & $2.5 \times 10^{7}$ \\
\hline $\mathbf{2 0} \boldsymbol{\mu m}$ & 26.5 & 2.3 & $2.4 \times 10^{-8}$ & -21 & $3 \times 10^{8}$ \\
\hline \hline
\end{tabular}

Table.2. 


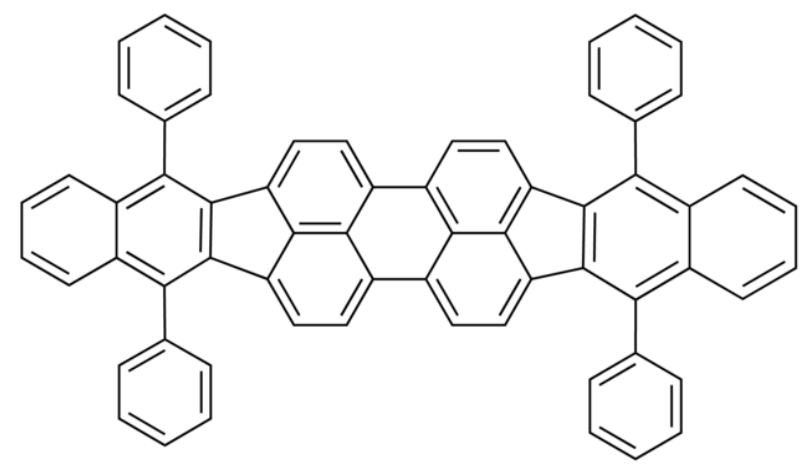

1.(a)

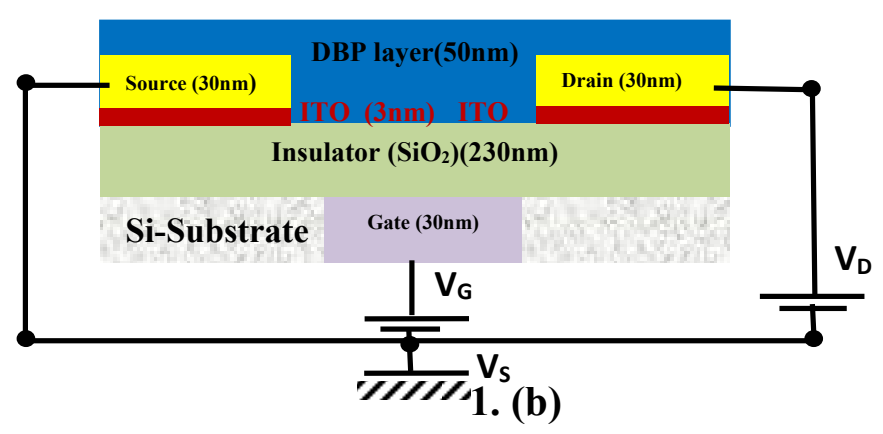

Figures 1. (a)-(b)
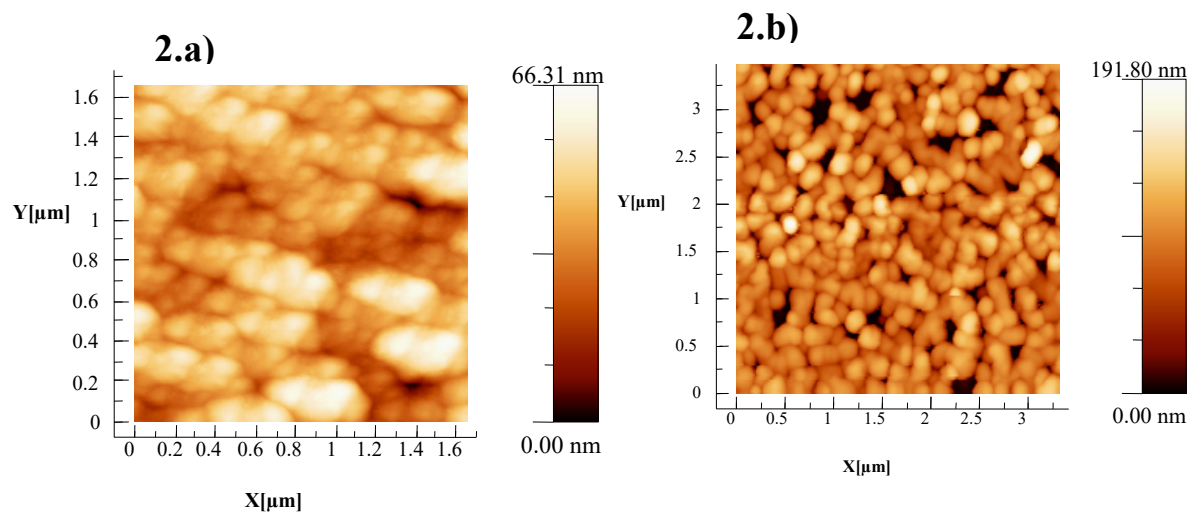

Figures 2. (a)-(b) 

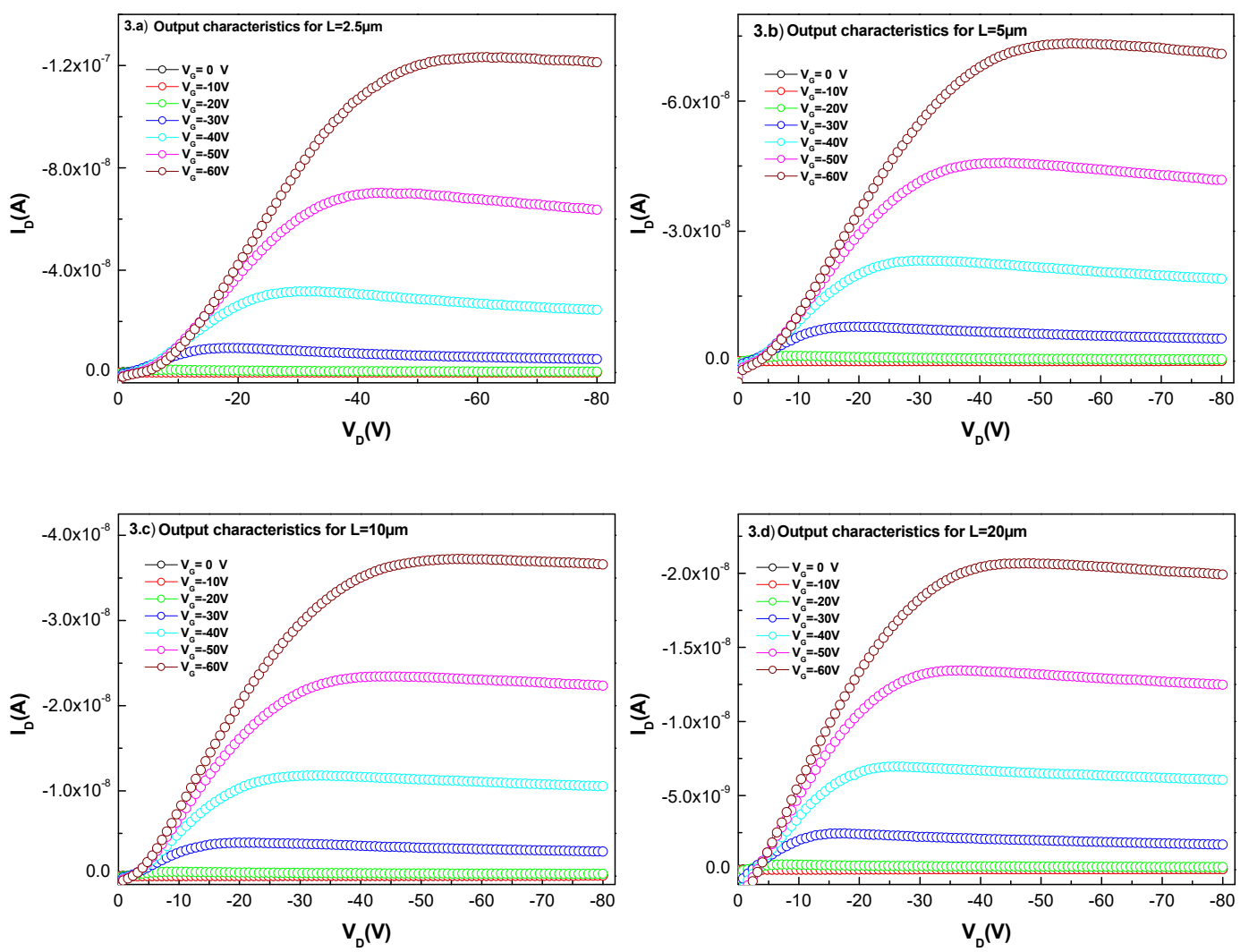

Figures 3.(a)-(d)

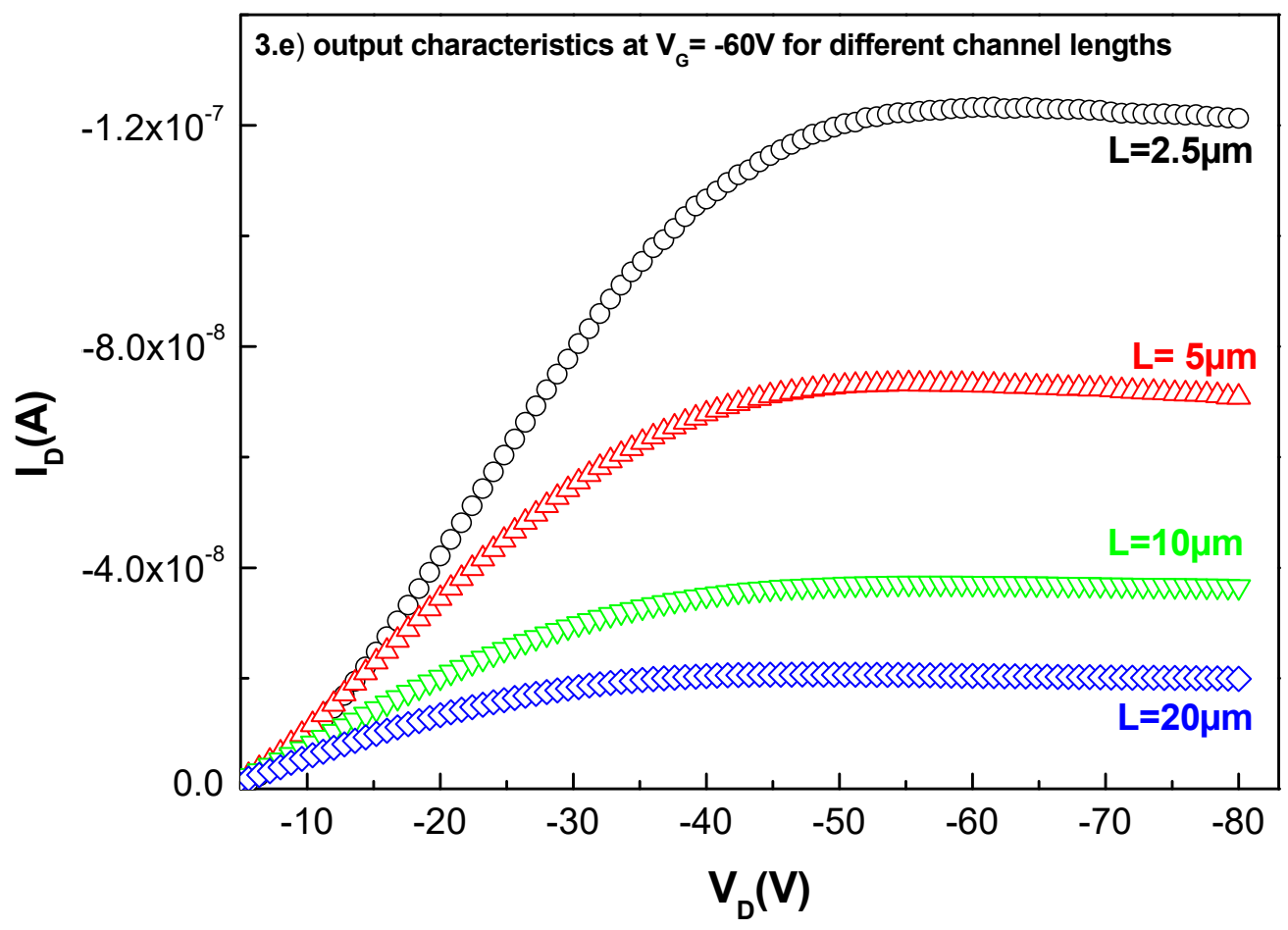


Figure 3. (e)
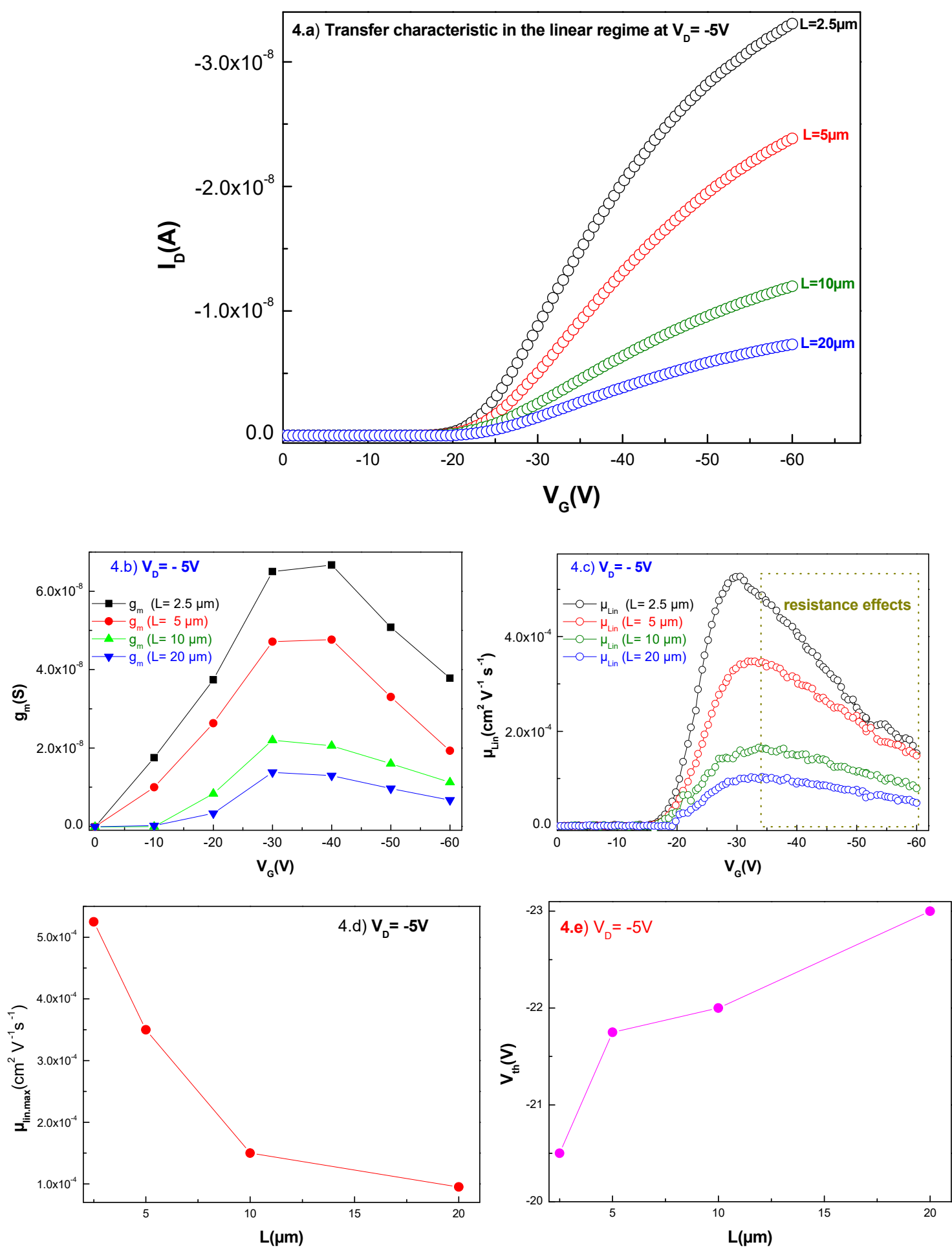

Figures 4. (a)-(e) 

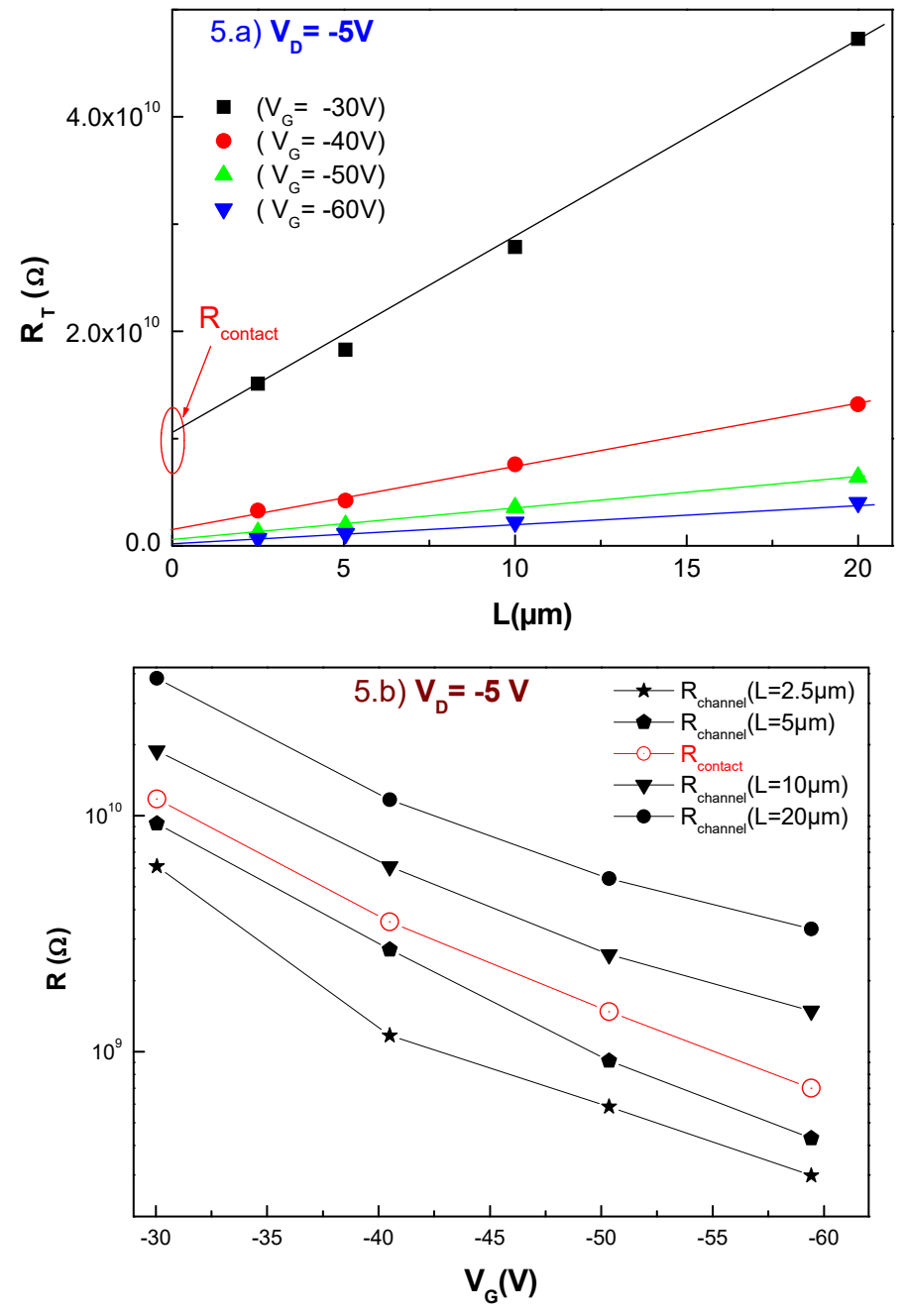

Figures 5. (a)-(b) 

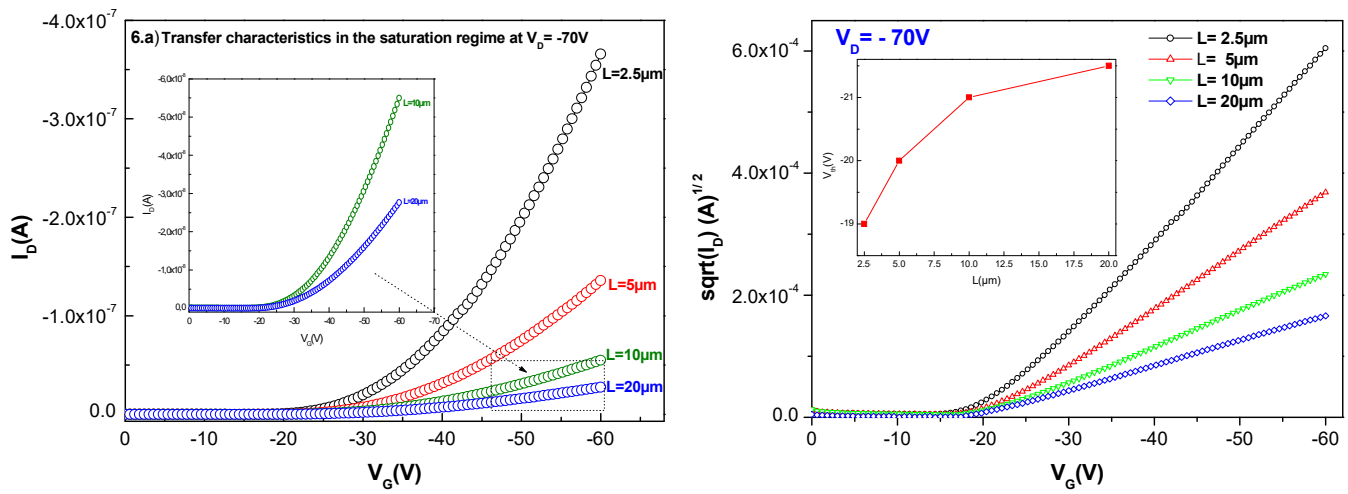

Figures 6. (a)- (b)
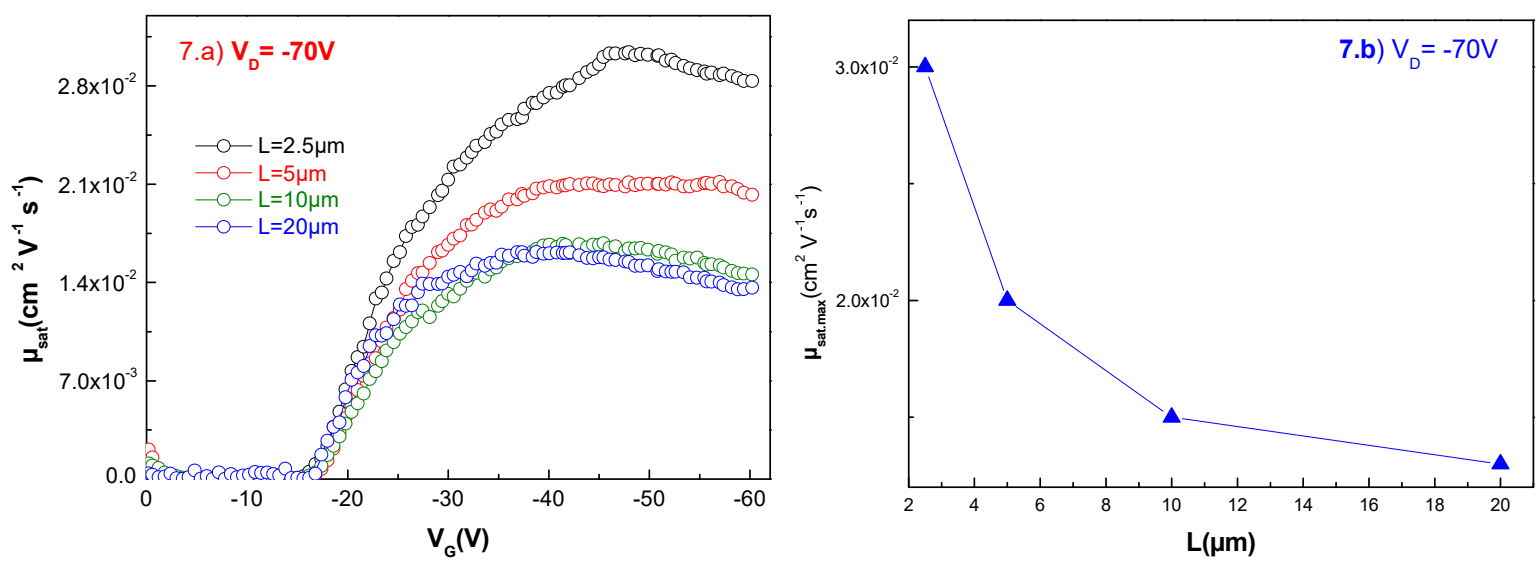

Figures7. (a)-(b) 


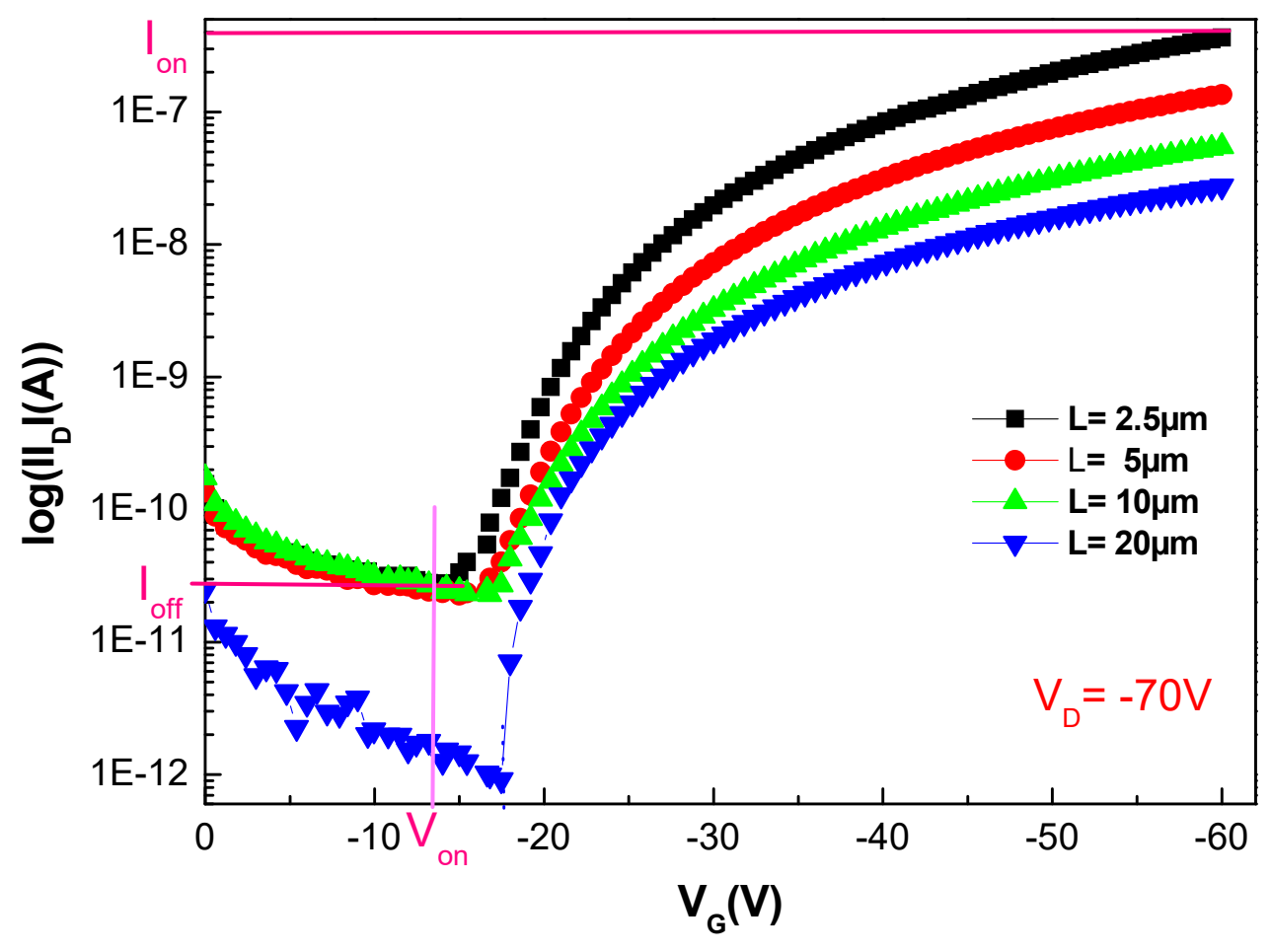

Figure 8

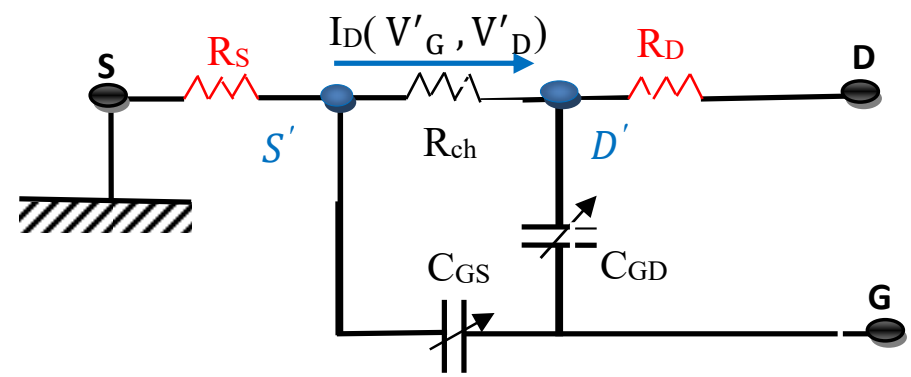

Figure 9 

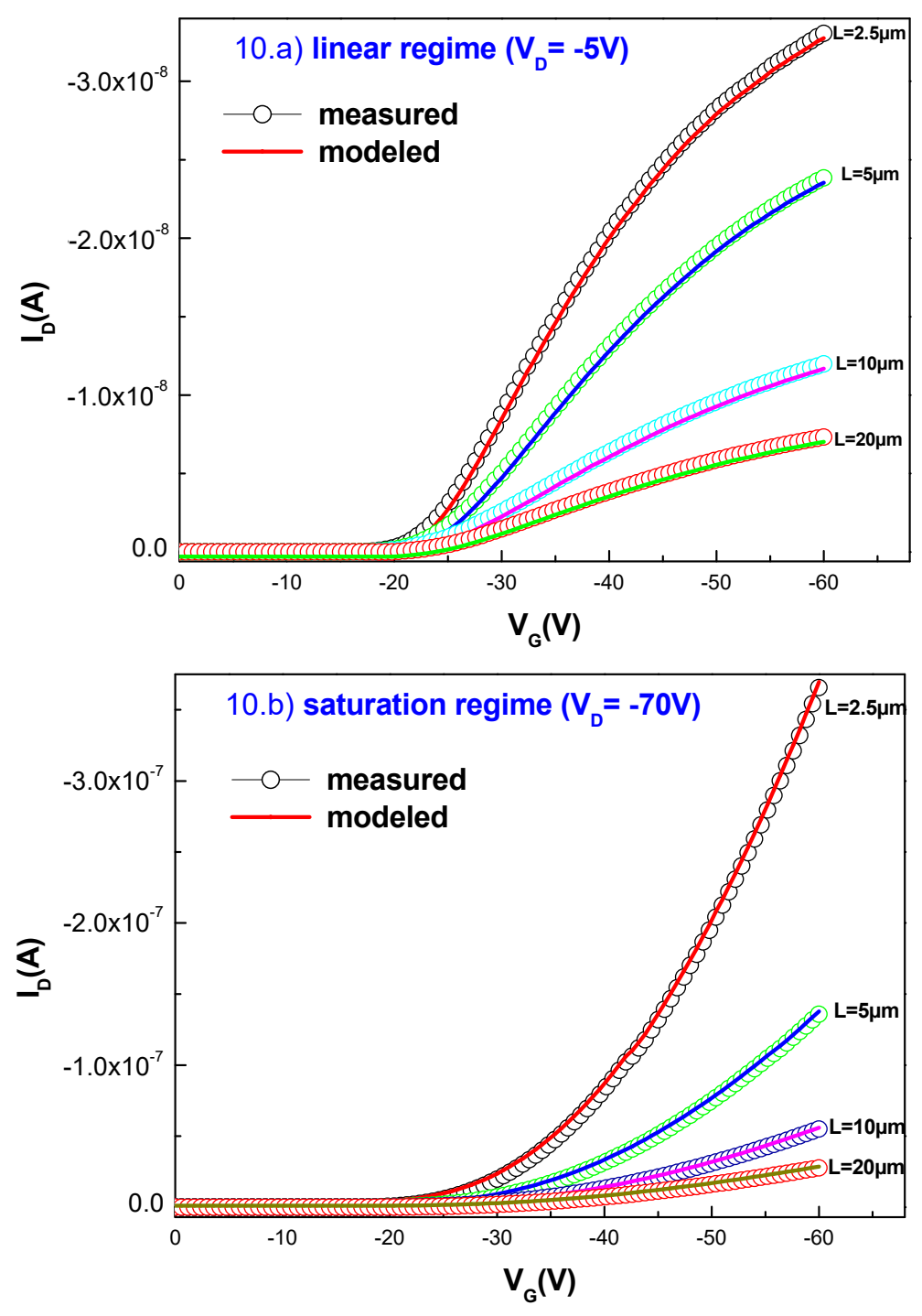

Figures 10. (a)-(b). 

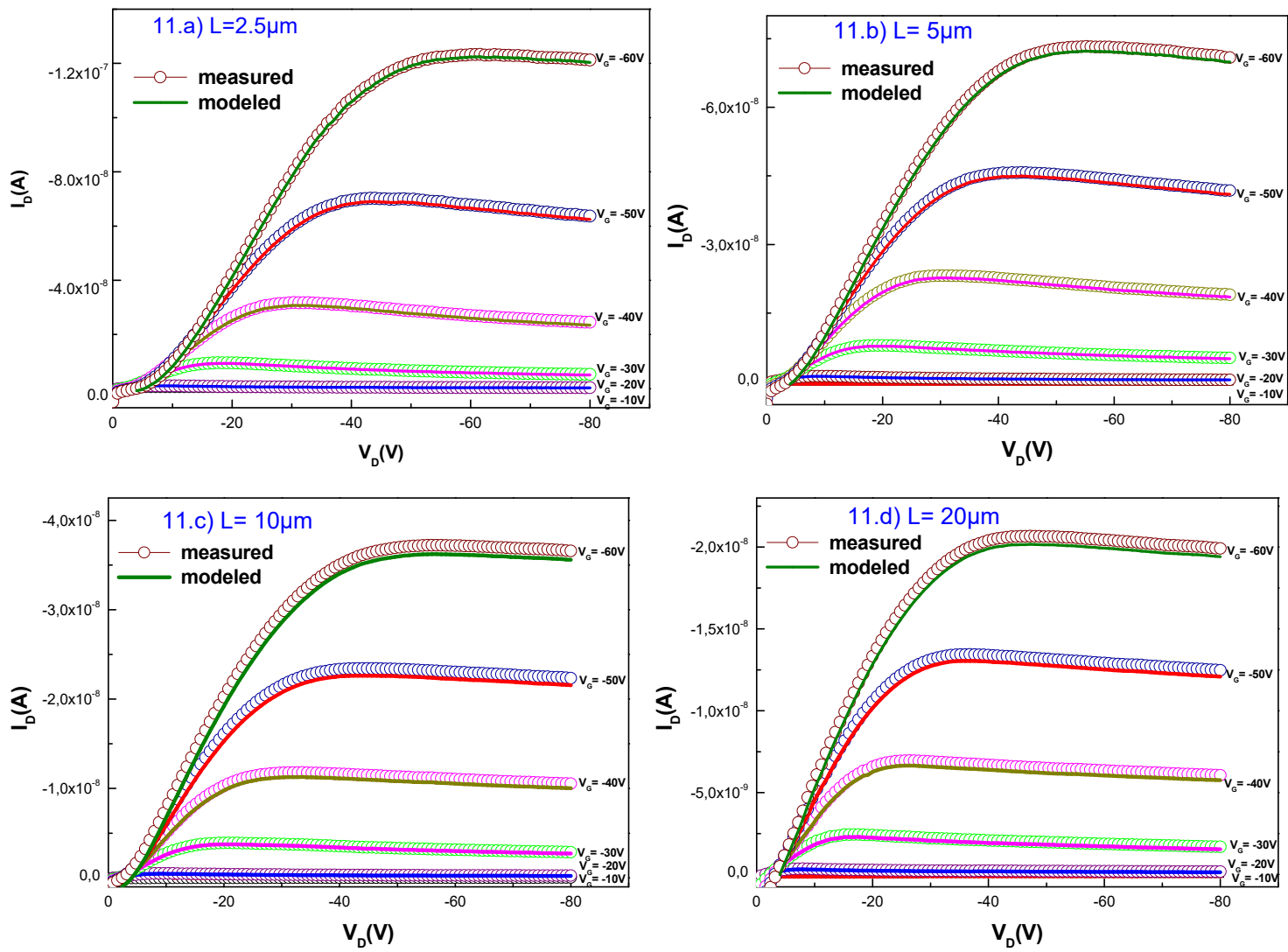

Figures 11. (a)-(d). 